\title{
Complex Micro Machining of an Injection Mold Surface for a Conductive Polymeric Composite Product
}

\author{
Daniiel Serban ${ }^{1, *}$, and Constantin Gheorghe Opran ${ }^{1}$ \\ ${ }^{1}$ University POLITEHNICA of Bucharest, 313 Splaiul Independentei, 060042, Bucharest, Romania
}

\begin{abstract}
Hydrogen and fuel cell technologies were identified amongst new renewable energy technologies which contribute strongly to mitigating climate change. Important research activities were directed to the injection molded bipolar plates made by conductive polymeric composites. The mold surface quality can help obtaining better conductivity. In this paper are presented the experiments regarding complex micro-machining of the surfaces of an injection mold for a conductive polymeric composite product by micro-milling and for finishing and cleaning by laser beam micro-machining. The laser ablation consists in removing material from a solid surface by irradiating it with a laser beam, in successive layers in order to achieve complex geometries with accuracy of about micrometres. Injection moulding experiments evidenced the very good replication of the micro-machined surface pattern.
\end{abstract}

\section{Introduction}

Fuel cells are electrochemical devices that convert chemical energy of the fuels into electrical energy. Today fuel cells are used to power vehicles including automobiles, forklifts, buses, boats, motorcycles or submarines. The European Union aims at reducing its greenhouse emissions by at least $20 \%$ and to increase the share of renewable energy at least $20 \%$ with a minimum $10 \%$ in the transportation sector; hydrogen and fuel cell technologies were identified amongst new renewable energy technologies.

The bipolar plates are important components of the fuel cell stack and must be highly electrically conductive to obtain a good voltage across the stack and highly thermally conductive to help cooling. Traditionally, the bipolar plates are made of graphite by milling or by steel by deep forming. Important activities were directed to the research of conductive polymer composites as an alternative material to reduce the costs.

Manufacturing micro machining technologies like chemical etching, high speed milling, electrical discharge machining, hybrid and sequential micro-machining were considered for the metal products fabrication, technologies which could be considered for the injection mould cavities too. According International Academy for Production Engineering (CIRP), a hybrid process is defined as follows: "Hybrid manufacturing process are based on the

*corresponding author: dserban@ddplast.ro 
simultaneous and controlled interaction of process mechanisms and/or energy sources/tools having a significant effect on the process performance" [1].

A sequential micro-machining process chain is described as the strategy whereby two or more micro-machining techniques are implemented in sequence on same or different machine tools. This is in contrast to hybrid micro-machining, as it was defined before, where two standalone machining technologies are integrated together. Building sequential micro-machining capabilities on a single machine tool could avoid realignment errors [2]. In this paper is presented a low-cost solution of a complex manufacturing system based on standard equipment (a fiber laser was added on a vertical machining centre's $\mathrm{Z}$ axis) with very good capabilities to obtain high precision (laser micro-machining) and good productivity (by milling).

The experiments consisted in combining the micro milling with laser ablation for the fabrication of the cavities of an injection mold for a conductive polymer composite bipolar plate.

\section{Micro-Machining}

The term 'micro-machining' refers to a machining process by which small bits of material are removed in order to achieve a high geometrical accuracy that otherwise is unattainable; in Table 1 are presented the range of the operation of the micro and macro machining [3].

Table 1. Extras of the range of operation of Micro and Macro Machining Processes [3]

\begin{tabular}{|c|c|c|}
\hline Type & Micro & Macro \\
\hline Surface machined & 1 to $100.000 \mathrm{~mm}^{2}$ & 1 to $100.000 \mathrm{~cm}^{2}$ \\
\hline $\begin{array}{c}\text { One Step Removal } \\
\text { Volume }\end{array}$ & $10^{-3}$ to $10^{2} \mathrm{~mm}^{3}$ & $10^{-3}$ to $10^{2} \mathrm{~cm}^{3}$ \\
\hline
\end{tabular}

Table 2. Micro-Machining Processes Classification [3], [4].

\begin{tabular}{|c|c|}
\hline Type & Process \\
\hline Physical & $\begin{array}{c}\text { Laser Beam } \\
\text { Electron Ion Beam } \\
\text { Electrical Discharge }\end{array}$ \\
\hline Chemical & Etching \\
\hline Electrochemical & Electrochemical \\
\hline Mechanical & $\begin{array}{c}\text { Milling, Turning, Drilling } \\
\text { Grinding, Polishing, Abrasive }\end{array}$ \\
\hline
\end{tabular}

In an interesting review focused on the diamond machining, including micro-chiselling (a process in which hexagonal prisms can be cut with dedicated diamond tools and a genuine cutting strategy), Brinksmeier and Preuss consider that the goal of micromachining is to achieve the required accuracy in one single machining step without being forced to iterate slowly converging machining [3].

Kuriakose et al considered the micro electrical discharge, laser beam, electron beam, ultrasonic and "electro stream drilling" (a negatively charged stream of acid electrolyte is impinged on the work piece from a finely drawn glass tube nozzle) as micro machining 
technologies for processing deep small dimensions holes in the fabrication of micro-electromechanical systems (MEMS), microfluidics and precision surgical instruments [4].

Micro injection moulding of a recycled polystyrene basis polymer was performed in a 4 cavity mold, for which the micro-pattern surfaces of each cavity were manufactured by a different process. The experiments evidenced the cost / precision ratio of laser ablation, micro-milling, electrical discharge and chemical etching technologies. Precision, replication, labour spent and $\mathrm{CAD} / \mathrm{CAM}$ considerations were discussed; it was observed the high precision of chemical etching and the difference of the work basis CAD/CAM files: engineering files step, iges 3D format for milling the cavities and the electrical discharge graphite electrodes versus 2D $d x f, p d f$ or $a i$ type files for laser and chemical etching processes [5].

\subsection{Micro-Milling}

Micro milling is a competitive process to manufacture small parts and to structure surfaces in high quality. Research activities were dedicated to the surface quality improvement and to reduce the tool wear. Investigations by kinematic simulations and experiments with single edge micro end mills with an effective milling cutter diameter of $50 \mu \mathrm{m}$ demonstrated the influence of the tilt angle of the spindle on the generated surface quality [6].

Comparison of the quality surfaces by micro-milling silicon carbide with a micro diamond tool evidenced the effect of applying a plasma jet in improving both the chip formation process and removing the surface contamination at the tool edge, obtaining a high-quality surface with a roughness $\mathrm{Ra}$ of $0.73 \mathrm{~nm}[7]$.

\subsection{Laser ablation}

The laser ablation consists in removing material from a solid surface by irradiating it with a laser beam, in successive layers in order to achieve complex geometries with accuracy of about micrometres. Laser ablation was applied successfully for producing micro structures and surface textures on miniaturised parts in the fields of biomedicine, microelectronics, telecommunication, aerospace, automotive and micro-injection moulding. [8]

Research works were directed to the accuracy, repeatability and reproducibility of laser micro-machining systems [8]. Restricted to scanner $40 \mathrm{~mm}$ x $40 \mathrm{~mm}$ field various geometries with different macro- and micro-structures can be $2 \frac{1}{2}-\mathrm{D}$ produced on generated steps from CAD data by the use of a laser scanning system with a highly precise beam; Larger fields can be manufactured using a X-Y-positioning, by sequencing of the single scanning areas. For deeper structures than $200 \mu \mathrm{m}$ the repositioning of the laser focus in $\mathrm{Z}$ direction is necessary.

The experiments with a Nd:YAG laser on micro-machining a microfluidics hot embossed tool shown that even very fine structures below $20 \mu \mathrm{m}$ with high aspect ratios can be replicated [9].

The experiments with a similar 5 axis laser equipment evidenced that machining of a simple planar surface laser beam was very precisely deflected by a system of mirrors without any change in the workpiece position but during machining of parabolic and spherical surface, it was necessary to deflect the laser beam and change the work piece position in the $\mathrm{X}, \mathrm{Y}, \mathrm{Z}, \mathrm{B}$ and $\mathrm{C}$ simultaneous and this can influence the accuracy [10]. 


\subsection{Hybrid Machining Laser Assisted Milling}

Thermally assisted machining is a method in which the material is softened with laser, plasma, electric arc, gas torch, or other sources prior to be machined. Hybrid systems lasermilling were analysed on machining a part in AISI 1045 steel and Inconel 718 and it was observed that for AISI 1045 steel, with laser-milling process, the cutting force decreased and surface roughness was improved as compared to conventional milling and for Inconel 718 with down cut milling, the surface roughness was improved for both conventional milling and hybrid laser-milling, and the cutting force with down cut milling was lower than with up cut milling [11].

Laser assisted milling normally has two configurations, where a laser beam is located next to a milling tool or integrated on a tool spindle; a study on an ytterbium fiber laser to assist micro-scale grooving of H-13 (DIN 1.2344) mould steel reported the accuracy improvement of the groove depth [12].

Recent reviews presented the hybrid additive and subtractive manufacturing processes methods which used an additive process to build a near-net shape which was subsequently machined to its final shape with desired accuracy by a subtractive process; new equipment and retrofit traditional milling machines with a laser cladding unit, in which first is deposited the material and then, higher surface finishes provided by milling operations [12].

\subsection{Sequential Machining Milling-Laser}

On a portal type machine tool for combined processes equipped with a revolving head supporting two milling spindles, one measuring system and one laser ablation scanner was produced a $62 \mathrm{HRC}$ tool steel microfluidic mold insert of $4 \mathrm{~mm}$ by $5 \mathrm{~mm}$ and a depth of 0.7 $\mathrm{mm}$ first by milling on NC paths generated from 3D part model. Then, it was deburred by laser ablation for which the paths were generated by following procedure : acquiring the geometry from the milled cavity (due to huge amount of data it was used a different computer), generating surfaces and then the export of the STL type file to the laser controller, were, the STL file is divided into the slices of a thickness corresponding to the material removal of one scanner path with constant machine tool axis z-position (in the range of $100 \mathrm{~nm}$ for finishing and a few micrometres for roughing, depending on material and laser parameters), then, the slices were hatched with a constant step $(10 \mu \mathrm{m}-20 \mu \mathrm{m})$ [13].

A technologic system in which were considered first laser structuring of the fine details and of the areas that cannot be machined using defined diameters of the milling machine, followed by subsequently micro-milling the rest of areas evidenced that sequential combination of micro milling and laser structuring enables processing of very fine geometrical details with dimensions of $<10 \mu \mathrm{m}$ [14].

\section{Experiments}

The experiments consisted in manufacturing the micro-structures of mold cavities for a bipolar plate with a combined technology micro-milling - laser ablation and injection molding the product in a conductive polymeric composite (polypropylene matrix and expanded graphite as filler). For the bipolar plate presented in Fig. 1 was built a mold in aluminium EN 7075. 



Fig. 1. The conductive polymeric composite bipolar plate 55 x $55-5 \mathrm{~mm}$, 3D Model and Injection Molded Product.

\subsection{The Complex System Micro-Machining Milling-Laser}

For the manufacturing experiments of the injection mold cavities was prepared a complex system, built on a 3 axis VMC (vertical machining centre) as basis, to which was added to the main spindle ( $\mathrm{Z}$ axis) with the help of a fixing device adapted to the SK40 tool holder the Galvanometer scanner head of a 20 -Watt Q-Switch fiber laser and a 24000-rpm spindle (as described in Table 3). The mold cavities were manufactured in aluminium EN7075.

Table 3. Complex system micro-machining milling-laser.

\begin{tabular}{|c|c|}
\hline Equipment & Specifications \\
\hline VMC -Vertical Machining Centre & $\begin{array}{c}\text { Strokes } \mathrm{x}=1000 \mathrm{~mm}, \mathrm{y}=700 \mathrm{~mm}, \mathrm{z}=700 \mathrm{~mm} \\
\text { Absolute Direct Measuring System } \\
\text { Controller: SELCA 3045P } \\
\text { (for all NC paths milling and laser beam } \\
\text { movements) }\end{array}$ \\
\hline Fiber Laser & $\begin{array}{c}\text { Pulsed Q-Switched 20 Watt } \\
\text { Galvanometer Scanner Head }\end{array}$ \\
& $\begin{array}{c}\text { Minimum diameter of the beam } 0.02 \mathrm{~mm} \\
\text { Controller: PC / software EZcad } \\
\text { (only for laser beam diameter) }\end{array}$ \\
\hline High Speed Spindle & $\begin{array}{c}24.000 \text { rpm, } \\
\text { air cooled }\end{array}$ \\
& Controlled by Frequency \\
\hline
\end{tabular}

\subsection{Micro-Machining Milling-Laser}

On the basis of few simulations, for micro-machining milling-laser were analysed the operations in the following sequence: rough milling, micro-milling, finishing micromilling, positioning (zero set) of the laser beam and laser ablation, as shown in Table 4.

During experiments it was evidenced the influence of the feeds to the stability of the system and there were analysed smooth profiles in order to reduce the acceleration / deceleration which could introduce vibrations. Schubert et al [9,13], Sugar et al [10] or Uhlmann and Essmann [14] presented a laser ablation method in which the laser beam paths are calculated on vectors extracted from hatched slices of the part to be machined and the laser beam movements controlled by the scanner with the optical mirrors system. 
Table 3. List of operations of micro-machining milling-laser performed on same VMC.

\begin{tabular}{|c|c|c|}
\hline Operation & Parameters/Tools & Controller/Program \\
\hline Positioning & Comparators & VMC's SELCA 3045P \\
\hline Milling & $\begin{array}{c}\text { Pocket strategy, } \varnothing 3 \mathrm{~mm} \text { flat end mill, } \\
\text { speed }=15.000 \mathrm{rpm}, \\
\text { feed }=800 \mathrm{~mm} / \mathrm{min}\end{array}$ & $\begin{array}{c}\text { VMC's SELCA 3045P } \\
\text { ISO 6983 (G-Code) }\end{array}$ \\
\hline Micro-Milling & $\begin{array}{c}\text { Pocket strategy, } \varnothing 0.8 \mathrm{~mm} \text { flat end mill, } \\
\text { speed }=22.000 \mathrm{rpm}, \\
\text { feed }=400 \mathrm{~mm} / \mathrm{min}\end{array}$ & $\begin{array}{c}\text { VMC's SELCA 3045P } \\
\text { ISO 6983 (G-Code) }\end{array}$ \\
\hline Micro-Milling & $\begin{array}{c}\text { Contour strategy, } \varnothing 0.8 \mathrm{~mm} \text { flat end } \\
\text { mill, speed }=22.000 \mathrm{rpm}, \\
\text { feed }=400 \mathrm{~mm} / \mathrm{min}\end{array}$ & $\begin{array}{c}\text { VMC's SELCA 3045P } \\
\text { ISO 6983 (G-Code) }\end{array}$ \\
\hline Positioning & $\begin{array}{c}\text { Laser beam and infrared beam (fig. 3) } \\
\text { Laser Ablation }\end{array}$ & $\begin{array}{c}\text { Galvano Scanner } \\
\text { PC EZCad }\end{array}$ \\
\hline $\begin{array}{c}\text { Parallel strategy, 45 } \text { steps of 0.02mm } \\
\text { (see fig. 2), Power=18 Watt } \\
\text { Frequency }=30 \mathrm{~Hz}\end{array}$ & $\begin{array}{c}\text { VMC's SELCA 3045P } \\
\text { ISO 6983 (G-Code) } \\
\text { PC EZCad for laser beam } \\
\varnothing 0.03 \mathrm{~mm}\end{array}$ \\
\hline
\end{tabular}

In contrast, on the technology presented in Table 3 only the laser beam is generated in continuous mode with the scanner as a circle of $0.03 \mathrm{~mm}$ diameter hatched with a step of $0.01 \mathrm{~mm}$ and the laser beam movements are calculated as paths on a parallel strategy with steps of 0.02 to $0.03 \mathrm{~mm}$ at $45^{\circ}$ controlled by the VMC's SELCA 3045P (fig. 2), the laser beam working as the tip of a milling tool of a $0.03 \mathrm{~mm}$ diameter.

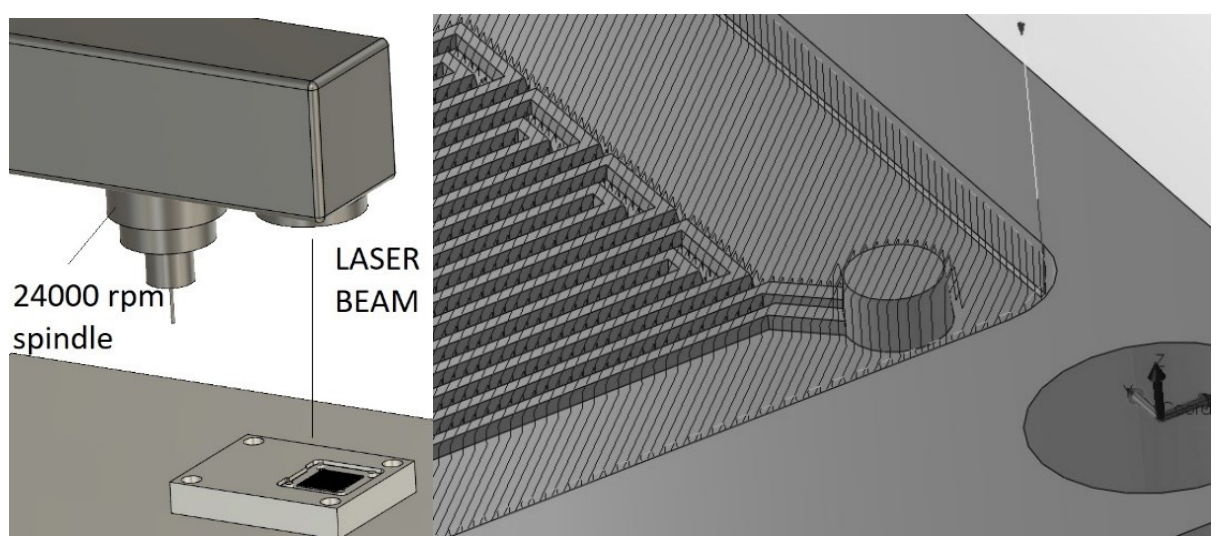

Fig. 2. a) The lay-out of high-speed spindle and laser galvanometer scanner mounted to the $Z$ axis of the VMC; b) The Parallel type strategy for laser ablation (the step distance is exaggerated in the image); the movements of the laser beam generated in continuous mode as a tool of $0.03 \mathrm{~mm}$ diameter are controlled by the VMC's Selca 3045P on ISO G-Code programme. 




Fig. 3. On the micro-machining milling cavity, it was engraved a set of circles and a cross for optical positioning the laser beam (1); image during laser ablation of Experiment E1 (2) and powder obtained from the thermal evaporation process (3).

Laser ablation (Fig.3 and Fig.4) was analysed with 3 sets of parameters, for beam speed and power and feeds on X-Y axis (as shown on Table 4 and Table 5).

Table 4. Parameters of the laser beam.

\begin{tabular}{|c|c|c|c|}
\hline \multirow{2}{*}{ Parameter } & \multicolumn{3}{|c|}{ Laser Ablation Experiment } \\
\hline & E1 & E2 & E3 \\
\hline Wave Length [nm] & 1064 & 1064 & 1064 \\
\hline Pulse Width [ns] & $90-130$ & $90-130$ & $90-130$ \\
\hline Power [Watt] & 18 & 16 & 18 \\
\hline $\begin{array}{l}\text { Maximum Energy of a single pulse } \\
{[\mathrm{mJ}]}\end{array}$ & 0.45 & 0.4 & 0.45 \\
\hline Frequency $[\mathrm{kHz}]$ & 40 & 40 & 40 \\
\hline Beam Speed $[\mathrm{mm} / \mathrm{s}]$ & 800 & 80 & 250 \\
\hline Focus Length [mm] & 189 & 189 & 189 \\
\hline $\begin{array}{c}\text { Diameter of the beam (generated as a } \\
\text { hatched circle) }[\mathrm{mm}]\end{array}$ & 0.03 & 0.02 & 0.03 \\
\hline
\end{tabular}

Table 5. Parameters of the CNC paths of the laser beam.

\begin{tabular}{|c|c|c|c|}
\hline \multirow{2}{*}{ Parameter } & \multicolumn{3}{|c|}{ Laser Ablation Experiment } \\
\cline { 2 - 4 } & E1 & E2 & E3 \\
\hline Feeds $[\mathrm{mm} / \mathrm{min}]$ & 800 & 500 & 700 \\
\hline Strategy of Paths & Parallel & Parallel & Parallel \\
\hline Step $[\mathrm{mm}] /$ Angle $\left.{ }^{\circ}\right]$ & $0.03 / 45$ & $0.02 / 135$ & $0.03 / 45$ \\
\hline Programming & $\begin{array}{c}\text { ISO 6983 } \\
\text { (G-Code) }\end{array}$ & $\begin{array}{c}\text { ISO 6983 } \\
\text { (G-Code) }\end{array}$ & $\begin{array}{c}\text { ISO 6983 } \\
\text { (G-Code) }\end{array}$ \\
\hline
\end{tabular}




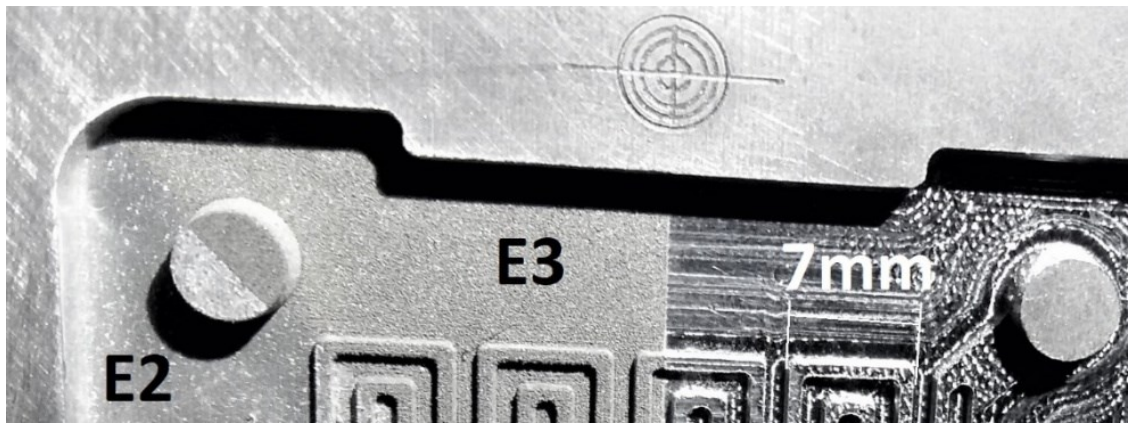

Fig. 4. Detail of the mold cavity surface micro-profiled by micro-milling (right side) and laser ablation experiments E2 and E3.

\subsection{Injection molding}

The injection molding was performed on a $350 \mathrm{kN}$ clamping force machine equipped with a screw of $30 \mathrm{~mm}$ diameter and a maximum injection pressure into the melt of $110 \mathrm{MPa}$. In to the mold electrical heated at $100{ }^{\circ} \mathrm{C}$ was injected at a pressure of $90 \mathrm{MPa}$ the melted polypropylene matrix with expanded graphite composite at $300{ }^{\circ} \mathrm{C}$. The experiments evidenced a very good replication of the micro-profiled surfaces (Fig.5).

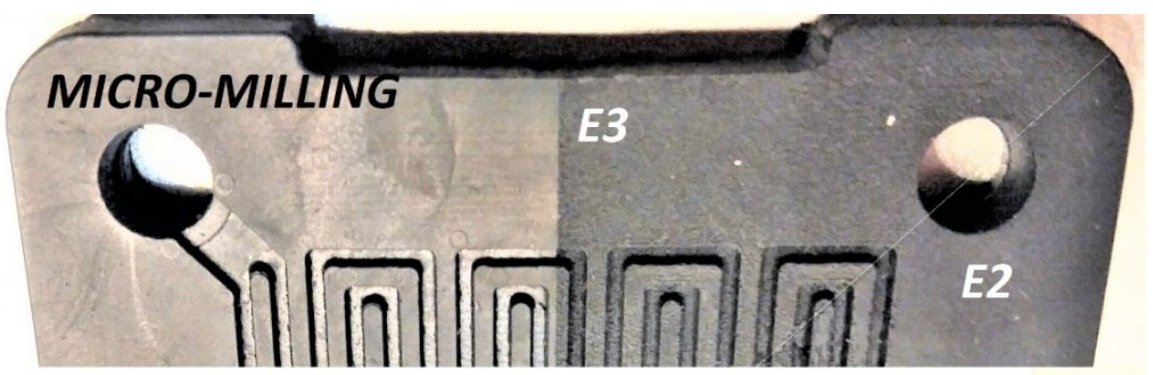

Fig. 5. Detail of the injection molded product, Micro-milling, E2 and E3 laser ablation surfaces.

\section{Conclusions}

The experiments with the micro-milling and laser ablation complex system configured on a Vertical Machining Centre on which was added a 20-Watt Q-Switched fiber laser galvanometer scanner on $\mathrm{Z}$ axis demonstrated the range of application of the method:

- As an alternative to micro-milling with tools under $0.3 \mathrm{~mm}$ diameter with possibility to work with higher feeds than carbide or diamond tools; good precision could be obtained versus the traditional controller of the laser beam when calibration must be evaluated;

- Pocket, Contour and Parallel machining strategies can be chosen for laser microprofiling; Project (vectors) on a 3D Surface could offer the possibility of engraving, micro-profiling precise structures on complex surfaces; Minimum retraction could influence a better quality of the micro-profiling the surfaces; 
- Combining micro-milling with laser ablation evidenced better productivity for microprofiling injection molds surfaces in the range of $100 \times 100 \mathrm{~mm}^{2}$.

- Laser ablation parameters are influencing the quality of the surface and the depth of the micro-structures; A second laser ablation with lower energy should be recommended for finishing the surface. Stability of the system by reducing the vibrations and feed optimization are challenges to be solved.

- The system could be a low-cost option for moldmakers and high precision tool shops; The laser controller will be used only for setting parameters of the beam and the paths programming with existing CAM Software. There is no need for correlation between the laser beam controller and the CNC Controller during micro-machining;

Further research work will be dedicated to the optimization of the laser parameters and evaluation of CNC paths strategies for an optimal system stability and productivity.

Acknowledgements. This paper was worked in the frame of $\mathrm{PhD}$ Student contract $\mathrm{nr}$. 06.71/01.10.2017 Daniiel Serban and Project PN-III-P1-1.2-PCCDI-2017-0194. The experiments were funded and performed on equipment of LS INTEH s.r.l., Bucharest, Romania.

\section{References}

1. B. Lauwers, Surface Integrity in Hybrid Machining Processes, 1st CIRP Conference on Surface Integrity (CSI) (2012)

2. S. Z. Chavoshi, S. Goel, P. Morantz, Materials \& Design, Volume 127, 37 (2017)

3. E. Brinksmeier, W. Preuss, Micro-machining, (Phil. Trans. R. Soc. A, 370, 2012)

4. S. Kuriasoke, A.V. Managlan, B. Nambothiri, A. Ray, Procedia Technology 25862 (2016)

5. D. Serban, C. G. Opran, IOP Conf. Ser.: Mater. Sci. Eng. 400032009 (2018)

6. J. C. Aurich, M. Bohley, I. G. Reichenbach, B. Kirsch, CIRP Annals, Volume 66, Issue 1, 101 (2017)

7. K. Katahira, H. Ohmori, S. Takesue, J. Komotori, K. Yamazaki, CIRP Annals, C, 64,129, (2015)

8. D. Bhaduri, P. Penchev, S. Dimov, S.L. Soo, Measurement 88, 248 (2016)

9. A. Schubert, S. Gross, J. Edelmann, B. Schulz, Physics Procedia 5, 261 (2010)

10. P. Sugar, J. Sugarova, M. Frncik, Open Eng. 6, 90 (2016)

11. Wan-Sik Woo, Choon-Man Lee, Applied Thermal Engineering 91, 33 (2015)

12. Z.Z. Dhokia, V.G. Nassehi, International Journal of Computer Integrated Manufacturing, 26, 596615 (2013)

13. A. Schubert, S. Gross, J. Edelmann, B. Schulz, LIM 2011, Physics Procedia 12, 221 (2011)

14. E. Uhlmann and J. Essmann, Proceedings 10th Anniversary International Conference of the European Society for Precision Engineering and Nanotechnology 2008, Zürich, Switzerland Bedford, Euspen, 1, 495 (2008) 